\title{
YOUNG SPEAKERS: A PILOT STUDY OF GAELIC BILINGUALS LANGUAGE PRACTICES
}

\author{
MICHELLE MACLEOD \\ University of Aberdeen \\ MARSAILI MACLEOD \\ University of Highlands and Islands
}

\begin{abstract}
Studies of primary school pupils' Gaelic to date have largely relied on criterion referenced tests to measure attainment against curricular expectations: with only NicLeòid's (2015) work on student attitudes and Nance's research (e.g. 2013 and 2015) on comparative phonology bucking this trend. There is a surprising lack of information or research about the language forms and bilingual repertoire of young speakers. A better understanding of young people's language practices requires the Gaelic research community to develop datasets from spontaneous interactions. This paper draws on a pilot study with a primary 5-6 school cohort in Gaelic-medium education. Using a combination of audio and audio-visual data from the classroom together with data on young speakers' language attitudes, this paper examines pupils' determination and strategies to maintain the classroom language as Gaelic. The results of this pilot study can inform the development of new methodologies for collaborative research with the school community on children's linguistic development and attainment. Such research, it is argued, is necessary in light of the dependency of the Gaelic language planning model on the primary school for the production of new Gaelic speakers.
\end{abstract}

Keywords: Gaelic, immersion, code-switching, primary school, language attitudes, language use

\section{Introduction}

Gaelic Medium Education (GME) has been the focus of much research in recent years. This article complements what has gone previously by both suggesting innovative ways of collecting language data in the classroom and in providing a commentary on students' language use within the classroom. Language 
education policy has been shown to impact both positively and negatively on language status, language acquisition and the attitudes of children to language (e.g. Baker 2006; Fishman 2006; MacLeòid 2007 and Hinton 2012). In situations of minority language revival and revitalisation the role of the school in language acquisition and language socialisation is highly significant because (a) it supports speakers' linguistic achievements in a sociolinguistic context where the language's use in other areas of public life is likely to be restricted and, (b) because the educational system produces new speakers, whose parents or care-givers may have no or only semi-fluency in the language. The education system plays, therefore, a vital role in ensuring the transmission from one generation to the next, and is a cornerstone of language revitalisation and reversal. Such is the power of the educational system that it is argued to be the most important mechanism of language shift to dominant, majority languages: "More than most other authoritative specialists, the authorities of the educational system are deeply implicated in planned language shift...Education [is] a very useful and highly irreversible language shift mechanism" (Fishman 2006: 320).

It follows, therefore, that reversing language shift requires bilingual education programmes to reverse the otherwise inevitable minoritisation of a language. As Hinton argues:

"It is a...(..)...sweet irony to use schools for language revitalisation since they
have played such a large role in language death. But language classes in otherwise
English-medium schools are not sufficient to create fluent speakers. Only a
serious bilingual education program can raise fluent speakers."

(Hinton 2011: 312)

A 'serious' bilingual education programme is, Hinton argues, an immersion model, which can enable fluency to be developed not only in L1 speakers, but in children whose first language is another language, and for whom intergenerational transfer in the family is not an option. The earliest appeal for such a model of bilingual education for Gaelic can be traced to the $1960 \mathrm{~s}^{1}$. However, it was only in the 1980s that a profound ideological shift in Gaelic in education policy occurred, and an additive bilingual model of education for L1 and L2 Gaelic speakers was implemented (see e.g. O' Hanlon 2015 for a history of Gaelic education). Dunmore (2017) notes that the Scottish Government and Bòrd na Gàidhlig (the national public body responsible for the promotion of the language) both align growth in GME with attempts to halt the decline in numbers of Gaelic speakers.

1 EDUCATION (SCOTLAND) BILL HL Deb 01 July 1969 vol 303 cc481-545. 
The prevalent system of Gaelic medium is bounded primary school 'units' in English-medium schools, the designation of a school in Skye as a 'Gaelic school' with an 'English-medium unit' in 2007 subverted the power geometry inherent in the 'Gaelic unit' model. Moreover, a further development is the creation of dedicated 'Gaelic schools'. Such bilingual immersion models, in their multiple forms, can and do lead to successful outcomes (Baker 2006) but, as Thomas and Roberts (2011) stress, minority language education is often challenged by a range of contextual factors which include the quality of education and opportunities for interaction in the minority language in school and in other social contexts.

As GME has now been established for more than 30 years, our knowledge around its practice continues to grow. Much has been published around the broad areas of: scholastic attainment and pupil motivation and loyalty, with less on linguistic attainment.

One of the earliest and most significant pieces of research on GME (Johnstone 1999) was in relation to levels of attainment across the curriculum. Johnstone (2000) and then O' Hanlon et al. (2010) found that "children are not being disadvantaged in comparison with children educated through English" and that "in many but not all instances they out-performed English-medium pupils and in addition gained the advantage of becoming proficient in two languages" (Johnstone 2000: 12). This is supported further by findings of O'Hanlon et al. (2010) where Gaelic medium pupils, by the end of primary school, were "judged by their schools to have reached the level of attainment expected of pupils at that stage (Level D of the 5-14 Curriculum)" in all four skills in English, Science and Mathematics (O'Hanlon et al. 2010: 22). In addition to attaining the levels expected of them in English, Maths and Science, results also indicated that most Gaelic medium pupils also attain this level in Gaelic reading, writing, talking and listening (ibid.), confirming that Gaelic medium children are not disadvantaged in terms of attainment in both Gaelic and English, Maths and Science. O' Hanlon also suggested that there is also weak evidence to indicate that in P7 and S2, "Gaelic-medium or Gàidhlig pupils might now have higher attainment than the English-medium of non-Gàidhlig pupils in English reading and writing" (ibid.: 20), perhaps demonstrating the advantages of bilingualism found in studies in other languages.

Much has been written about the role of motivation in second language acquisition and usage. With regard to Gaelic in primary schools NicLeòid's (2015) qualitative research with 80 primary and secondary GME pupils demonstrates that the majority of pupils are motivated and comfortable in

2 The first Gaelic primary school opened in Glasgow in 1999; currently there are seven Gaelic medium primary schools. 
speaking Gaelic and that these attitudes were not connected to their competency or the amount of Gaelic children had in the home. NicLeòid did note, however, that this confidence dipped when school pupils were face with different situations outside of school and when they left primary school. NicLeòid postulated that this dip in motivation and confidence could be down to the reduced number of classes taught through the medium of Gaelic (NicLeòid 2015: 118-9). Dunmore's extensive work (2014) with GME leavers, however, has shown that adults who are products of the GME system are "making low to limited use of Gaelic at present" (Dunmore 2014: 272-3); this he has surmised from 130 questionnaires and 46 interviews with adults, 36 out of the 46 no longer using Gaelic.

One of the surprisingly lesser-researched areas is that of linguistic attainment: how successfully are children acquiring Gaelic and what type of Gaelic are they acquiring. In terms of meeting school targets for language skills there is some evidence that Gaelic-medium pupils' attainment in English overtakes their attainment in Gaelic by P7 (O' Hanlon et al. 2010), and although pupils in Gaelic-medium were judged to have attained the expected level for Gaelic in Primary 7 there seems to be a noticeable gap between attainment in Gaelic and attainment in English (O'Hanlon et al. 2010). This small case-study goes some way to help the research and education community understand language practice and ideology in a Gaelic classroom.

\section{Research Method}

A case study approach was adopted for this study since a 'single instance of a bounded system, for example... a class, a school, ... provides a unique example of real people in real situations' (Cohen et al. 200: 181) which can be designed to illustrate a more general principle (Nisbet and Watt 1984: 72) and can be used as an exploratory pilot study for future research. Whilst open to wide interpretation, a case study facilitates investigating a phenomenon (i.e. language use) in context whilst drawing on a variety of data sources and methods. This allows investigators to retain the holistic and meaningful characteristics of reallife events and to construct the understandings from multiple facets and lenses (Creswell 2012; Stake 1995; Yin 2009). Since the research lies at the intersection of social, linguistic and pedagogic factors, it was important to enable different types of data to be gathered which would enable a wider picture to be understood. That is, classroom language which encompasses learning and social interaction is inextricably linked to the pedagogic environment and the individuals within. Focussing on one element in isolation could only present a partial picture. 
In order to collect linguistic and pedagogic data in situ, it was decided to use a mixed methods interventionist approach which would try to elicit pupil language from a data-rich setting where pupils were encouraged to interact through tasks including group work and teacher dialogue. The regular teacher preferred the research team to set up tasks and activities which would generate data rather than design the tasks herself. Methods included a language-rich series of tasks involving pupil participation in class, in groups and individually to generate a multiple data source combination of audio and visual recordings of language collected in situ, written examples of language practice, participant self-reporting on language attitude and usage, and pupil observation. Interviews with teachers at this school into the experiences of learning and teaching Gaelic in primary were also collected.

The data fall into three types: language corpus data, to be analysed using content/discourse analysis to understand the nature of the language used and its linguistic features; qualitative and quantitative attitudinal data, to generate an understanding of how learners perceive their own Gaelic language 'performance', and that of others; and pedagogic data to understand better the role of the classroom context, approaches to learning and the tasks used to support learning, supplemented by the teacher interview data.

In order to collect natural language data we worked with a school in a traditionally 'Gaelic-speaking community': this school had equal numbers in its Gaelic and English streams. Once ethical approval was sought from all parents, data was collected over a two-day period in composite class 5-6. This class was chosen in consultation with teachers as it was believed that by this stage all pupils would be confident Gaelic speakers and happy to speak to us. There were 18 pupils in the class and they all participated to varying degrees in the research. Only three children had Gaelic in the home as a daily language: others heard the language by extended family members and neighbours and some had no contact with Gaelic outside of school.

In order to collect the language data one of the researchers (a qualified GM primary teacher) carried out a lesson focussed on 'islands', real and imaginary: after the pupils had discussed different types of islands as a group, they were given the following tasks which enabled data collection:

1) Pupils were split intro groups of twos or threes to 'create' an island. While they worked their conversation was recorded using small recorders on their tables. This provided examples of natural language usage.

2) Working in pairs, the pupils interviewed each other about their islands using small video cameras: pupils took it in turns to interview their class-mates. This exercise provided data linked to language performance. 
3) We conducted interviews in pairs with 10 children in the class: being guided by the class teacher we were able to ensure different family language backgrounds were represented. We also conducted a survey on paper with all class members: these two data sets provided us with useful qualitative information.

4) We interviewed both the class teacher and the deputy head teacher (in charge of GME in the school) to find out what they thought about the children's language skills and needs and to ascertain, also, what teaching materials they used to develop the children's language skills (We do not go into this data in this article).

Although we collected data for every child in the class, four children were selected, in collaboration with the teachers, to perform detailed analysis on their language usage: one pair had Gaelic in the family and one pair did not have Gaelic in the family. We then compared the language use and patterns of these two pairs.

\section{Language Use Analysis}

Our conversation analysis here focuses largely on code-switching. Using a method based loosely on Auer's (1984) conversation analytic approach to codeswitching, we are able to focus on both the sequence of the conversation and the influence of the turns that are being exchanged.

\section{Pair A: Children with no Gaelic in the home}

We found that Pair A (Hazel and Christopher) were actively involved in upholding Gaelic as the normative language of the classroom. The children worked together to reach mutual comprehension by deploying a range of strategies to negotiate linguistic gaps and to express their ideas in Gaelic. The use of the speech fillers 'mar', which itself is a calque of the English speech filler 'like', and 'an uair sin' (then) were commonplace: there were 25 uses of 'an uair sin' and 193 uses of ' $m a r$ ' in 30 minutes of their recorded speech. The use of such fillers signalled to their interlocutor that they were still speaking, whilst giving the speaker time to consider how to express themselves.

Unassimilated word borrowings from English were consistently preceded by the filler ' $m a r$ ', as Hazel or Christopher actively searched first for the Gaelic lexicon before uttering the English word. Whilst English speech fillers such as 'right' and 'like' were used, English borrowings were mainly concrete nouns. In the example given below, Hazel and Christopher discuss the weather typical of their imaginary island. This example serves to illustrate how they determine 
how to express a concept which they express in English, 'mixed weather', in Gaelic.

Example 1

1 HAZ: a bheil e dol a bhith mar (0.2) fuar?

2 CHR: uill's docha(0.6) tha mi a'smaointinn

Well perhaps I think

eil fhios agad ma bha e ann an Dubai [?]

you know if it was in Dubai

(0.5)

bidh e math ma bha e mar huge mar smiley face

It will be good if it was like a huge like smiley face agus taighean ann agus rudan eh:

3 HAZ: so mar (0.5)

no a bheil e direach dol a bhith mar an t-Eilean Sgitheanach

or is it just going to be like the Isle of skye

mar uaireanan tha e blàth agus uaireanan tha e fuar $\uparrow$

4 CHR: $\quad$ Yeah $\uparrow$.so mar mixed. A bheil facal airson sin $\uparrow$

5 HAZ: $\quad$ uill - 's dòcha direach mar sgrìobh mar (0.9)

Well perhaps just like write like

uaireanan blàth uairean teth uaireanan

seomtimes warm and sometimes hot

((they look in the dictionary))

6 CHR: Measgaich ((uncertainly))

Mix

dè tha weather?

What is weather

7 HAZ: (l aughing) mar mix.ich.te mar blàth agus fuar

Like, mixed like warm and cold

8 CHR: Oh yeah. mixichte mar blàth agus fuar

Oh yeah. Mixed like warm and cold

so tha sinn direach a' sgrìobhadh sin

So we are just writing that

In Turn 4, Christopher identifies 'mixed' as essential information for the task, whereas Hazel suggests the same meaning can be conveyed by describing the weather as 'sometimes cold and sometimes hot'. It is evident in Turns 3, 5 and 7 that Hazel does not see any need for the adjective 'mixed', but Christopher does and thus looks it up in the dictionary. In Turn 6 Christopher locates the noun, 
'mix' but does not know how to form the adjective, 'mixed'; nor does he know the Gaelic for 'weather'. Patiently, Hazel contributes the adjectival ending, but maintains again in Turn 7 that the English equivalent is not necessary, resolving the problem with a compromise: 'mixed, sometimes hot and sometimes cold'. In this example, the use of the dictionary coupled with peer feedback resolved the problem, and the peer imitation in Turn 8 exemplifies how their collaborative negotiation of the task is connected to Gaelic language learning.

The excerpt not only illustrates their communicative strategies: it also highlights that lexical gaps are only seen as problematic if they are essential to the task of describing their island to others in performed speech. We see that no Gaelic description was sought for 'huge smiley face'. They proceeded to draw a 'huge smiley face' on their paper. If the lexicon is not identified by the children as essential information to convey in the performative task, then the English word is borrowed to meet the momentary needs and goals of their interaction. Indeed, we found that the majority of gaps were, unresolved, with neither child seeking to convey the meaning in Gaelic, for example, for 'city', 'in between', 'instead of', 'lawyer', 'size', 'straight', 'pier', 'hidden', 'kind-of', 'memorial', 'walking stick' or 'sort-of'.

The example below illustrates several other ways in which lexical gaps are resolved. Whilst Hazel and Christopher's use of English was largely unassimilated, their speech did contain some examples of assimilated English lexicon. One recurring type of assimilation was through adding the Gaelic verbal morpheme - (e)adh to English verbs, as illustrated by Christopher's use of fligheadh (for 'flying') in Turn 2. The children would also propose descriptive alternatives to English terms, such as the example in Turns 14 and 16, when Christopher proposes 'litter picker' as duine sgudal (litter man). 
Example 2

1 HAZ: agus mar dè obraichean a bhith aca?

And like, what jobs will they have?

2 CHR: emmm (0.8) a' feuchainn ri faighinn muc a' fligheadh ((laughter))

3 HAZ: what $\uparrow$ No, mar, a bheil mar tuathanach no $\operatorname{mar}$

What? No, like, are like farmers or like...

4 CHR: Obraichean inntin-, inntinneach mar - a' feuchainn ri faighinn

Interest-work, interesting like - trying to get

daoine ann an adhar ach >chan eil $\uparrow$ fhios am<

people in the air but. I don't know.

5 HAZ: A bheil e dol a bhith mar obraichean bho mar city mar

Is it going to be like jobs from like a city like

6 CHR: Obraichean ma[r]

Jobs like

7 HAZ: [la]wyer agus rudan mar sin no ag obrachadh mar air

Lawyer and things like that or working like on

tuathanach? (0.7) No mar daoine ag obair air an tràigh

a farm? Or like people working on the beach

8 CHR: ((laughs))

9 HAZ: $m a[r]$

like

10 CHR: ["Sand] (0.4)get your free sand here" ((singing))((delineating character))

11 HAZ: ((laughs))

12 CHR: Ok right

13 HAZ: no mar tha iad chan eil fios agam. No mar bidh iad a' dèanamh

Or like they are I don't know. Or like they will be making cinnteach mar nach eil mar sgudal sam bith [air an tràigh]

sure like there isn't any rubbish on the beach

14 CHR:

\section{HAZ: Yeah tha e mar] \\ Yeah, it is like \\ 16 CHR: [duine sgudal]}

[Ok so, mar] litter picker

Ok, so like a litter picker

$$
\text { a litter man }
$$

In only one instance was English used as a discourse marker: in this instance to delineate Christopher's speech from the character being depicted on the drawing, when he sings, "sand, get your free sand here!" in Turn 10.

When the word gap was deemed essential to the task, but could not be filled by consulting the dictionary or thesaurus, Dòigh eile air a ràdh (MacLeòid 2008), Hazel asked a teacher e.g. for a way to express 'secret' and 'seafood'. 
These examples show how the children sought to sustain Gaelic as the normative language of the classroom and worked collaboratively to resolve any language problems in successfully completing their task. Pupil feedback on lexical errors was minimal in Pair A, with no evidence of feedback on phonological or grammatical errors.

\section{Pair B: Children with Gaelic in the home}

In contrast to Hazel and Christopher, Seòras and Calum's conversation was monolingual Gaelic and there were very few examples of either assimilated or unassimilated English lexicon or of code-mixing or switching. Whereas Hazel and Christopher's use of English was essential for communicating meaning, Seòras and Calum's use of English was primarily for getting attention and for affect. While their Gaelic speech contains examples of lexical gaps, these gaps are typically overcome by finding alternative words and phrases for expressing meaning. Their dialogue is characterised, therefore, by self-repair and corrective feedback. In the example below, Seòras is interviewing Calum about his hobbies. The example demonstrates their efforts to express the Gaelic for 'playing the bagpipes'. In Gaelic, the idiomatic way to express playing the bagpipes is through using the verb 'to sing'. In Gaelic 'bagpipes' is a singular feminine noun which, following the verbal noun and compound prepositions, takes the genitive case: at least according to grammatical norms.

\section{Example 3}

1 SEÒ: Dè na cur-seachadan a th'agad $\uparrow$

What are your hobbies?

2 CAL: We::ll, is toil leam a' cluich ball?-coise heh ((smiles)) is iom $\uparrow a i: n$ is am Well, I like playing football and shinty and the Playstation.

Playstation

3 SEÒ: Inntinneach. Agus dè mu dheidhinn a' phìo $\uparrow$

Interesting. And what about the pipe

4 CAL: Dè?

$$
\text { What? }
$$

5 SEÒ: Dè mu dheidhinn na phìob $\downarrow$

What about the pipes?

6 CAL: Oh yeah bidh mi a' cluich na phìob bidh mi a' seinn na phìob is a' cluich a' bhocsa.

Oh yeah, I play the pipes, I sing the pipes and play the box

7 SEÒ: $\underline{\text { Inn }} \downarrow$ tinneach. Tapadh leibh $\uparrow$ Calum.

Interesting. That you (pl.) Calum. 
In Turn 3, Seòras asks whether Calum plays the bagpipes, using the nominative rather than genitive case, as indicated by the article $a^{\prime}$. Calum's retort of 'What?', which may be intended to provoke self-correction, gives Seòras the opportunity to self-repair, this time by marking the genitive case with the article for single feminine nouns, $n a$, in Turn 5. Calum, in his reply, first uses the verb $a^{\prime}$ cluich (playing) but then self-repairs with the idiomatic verb $a^{\prime}$ seinn (singing). Like Seòras, he lenites the noun, na phiob, whereas the article na blocks lenition, according to accepted norms. Note that in Turn 2, the English term 'playstation' is assimilated by use of the definite article for labial consonants, am.

As a likely consequence of a relatively higher level of Gaelic input in the home, Pair B are generally able to fill any lexical gaps independently of the support from written resources or a teacher. The example below illustrates how Calum seeks to resolve Seòras' use of the English term 'port area', when discussing who will draw what.

Example 4

1 CAL: Nì mise beagan eile an seo.

I will do some others here.

2 SEÒ: An nì mise mar (.) port area airson na bàtaichean?

Will I do like a port area for the boats?

3 CAL: (3.0) Port area?

Port area.

4 SEÒ: Mar airson na bàtaichean a'tighinn a-staigh.

Like for the boats coming in.

5 CAL: O::h $\downarrow$ (0.6) yeah feumaidh tu a' dèanamh sin. (.8) cidhe $\uparrow$

6 SEÒ: Cidhe. Sin an ainm a tha air. Ok.

Pier - that's its name - ok.

7 CAL: Nì mise am fear sin.

I will do that one.

8 SEÒ: Yeah. Ni (.) thusa am fear sin.

Yeah. You will do that one.

9 CAL: Nì mise am bùth a tha seo. (12) Dè mu dheidhinn drochaid

airson airson dol air mar (3) airson dol gu emm (0.4), dè an ainm a tha air (1.5) am baile mòr?

I will do the shop. What about a bridge for emmm doing to emm. What's the name of the big town? 
10 CAL: Am baile mòr?

The big town?

11 SEÒ: Dìreach drochaid airson dol (1.5) agus bidh drochaid a' dol gu mar:: sin agus sin.

Just a bridge for going and there will be a bridge going like that and that.

(18) Agus tha craobh beag an sin agus (.)cidhe. ${ }^{\circ}$ An nì mi oh no $\sin e .^{\circ}$

And a little tree here and a pier. Will I do, oh no, that's it.

12 CAL: (1.5)Tha sin a' coimhead math.

That looks good.

13 SEÒ: Aidh gu dearbh.

Aidh indeed.

Calum's querying of, 'Port area?' prompts Seòras to explain in Turn 4 what he means in Gaelic, enabling Seòras to supply an appropriate Gaelic term, cidhe. Calum is motivated to address such lexical gaps, but he doesn't seek to repair Seòras' grammatical 'errors'. For example, Seòras is using the independent form of the verb, ni in Turn 2, instead of the norm of the dependent form, but Calum does not recast or give any other cues for correction.

Summary of Code-switching and Mixing

To summarise, we found that both pairs of children were actively involved in sustaining Gaelic as the normative language of the classroom, with little switching within conversational turns or between turns. Switches to English were used primarily for effect, such as to impersonate a character, or as a discourse organisational tool, such as capturing the attention of classmates. The children strived, therefore, to use Gaelic and English as separate codes.

Borrowing from English was prevalent in Pair A's natural speech, which the data suggests is due to the competence of speakers, but largely absent in Pair B's natural speech. In Pair B, the use of English in speech was 'marked' (Myers-Scotton 2006); it typically aroused attention, with the exception of English internationalisms, such as Playstation. However, Pair A used 'borrowing' as a conversational strategy in the moment of interaction as they negotiated what form their island might take. When attending to the task of being able to describe their island to others in 'performed' speech, they strived to overcome lexical gaps in their Gaelic. As such, to be able to achieve the task, they deployed a range of discursive and practical strategies to ensure they could communicate meaning in Gaelic alone to their classmates. 
Whilst McLeod (2004) notes that most Gaelic speakers, when faced with a lexical gap, will tend to simply insert the relevant English word into a Gaelic sentence, and Will (2012) notes that code-switching and mixing is the 'norm' in the adult community, the monolingual ideology of the classroom means children resist borrowing or mixing in pupil talk. Section 4 below draws on interview data to explain how the children rationalised these choices and practices.

\section{Language Attitudes}

This section draws on our findings from the pupil interviews and surveys, which explore children's own perceptions of their bilingual proficiency and their language practices, before examining their affective beliefs towards Gaelic and their Gaelic-speaker identities.

\section{Introduction to Pupils' Attitudes}

Our survey and interviews further explored the children's perceptions of their own competence, and their attitudes towards using Gaelic and English. In the survey, the eighteen children in the class were asked to respond to 11 statements using a 5-point agreement scale. The scores were reversed for negative statements (2/6/10) and mean scores calculated, whereby a score of 5 represents a very positive attitude and a score of 0 a very negative attitude:

Their perception of others' attitudes towards their identity

as Gaelic speakers $(2 / 10 / 7)$

Their attitudes towards using Gaelic (1/6/9)

Their own expectations of their future use of Gaelic (4/3/8)

Their attitudes towards bilingualism (5/9)

Overall, we found that children generally held a very positive attitude towards the Gaelic language. The children were more positive about the perception of others towards their identity as Gaelic speakers (4.3) and towards bilingualism (4.5) than they were about their language practices, both current (3.4) and expected (3.8). The results suggest that the children did not see their Gaelicspeaking identities as conflicting with their identities as pupils of this school: none identified that other children in the English stream teased them for being a Gaelic speaker, although only three children felt that non-Gaelic-speaking pupils might be envious of their bilingualism. The majority of children (fifteen) agreed or strongly agreed that their parents wanted them to continue learning 
Gaelic in high school and the same proportion agreed that they wanted to continue to learn Gaelic in school: only one disagreed with this statement. The majority of children perceived their own aspirations to be in keeping with the aspirations of their parents; however, two children believed they held contrary views to their parents. One child wanted to continue to learn Gaelic, but perceived his/her parents might disagree and another child did not wish to continue learning Gaelic whilst his/her parents were ambivalent.

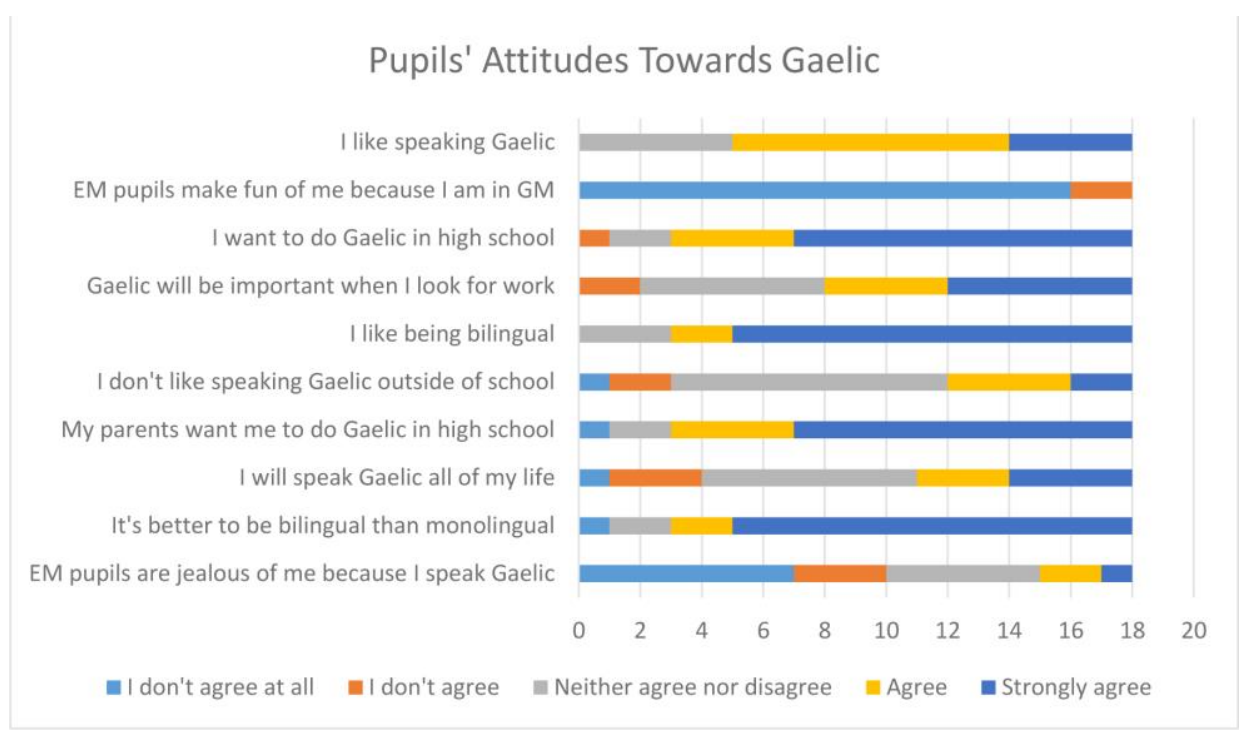

Figure 1: Pupils' attitudes towards Gaelic

The children expressed less certainty regarding the role of Gaelic in adulthood. Whilst ten agreed or strongly agreed with the statement 'Gaelic will be important for when I am seeking work', only seven children agreed with the statement 'I will speak Gaelic all my life'. Our interviews suggest that this uncertainty reflects pupils' awareness of the small numbers and concentrations of Gaelic speakers and a lack of confidence in its relevance beyond their education. Pàdraig explained that, whilst he'd like to speak it in later life, that:

"Maybe mar... maybe dhiochuimhnich sinn beagan dheth ach Gàidhlig fhathast againn. "Maybe like maybe we will forget some of it but we'll still have Gaelic."

During interview we explored the children's beliefs about the geography of Gaelic in Scotland. When asked if many people spoke Gaelic in Scotland, one pupil explained: 
"Well, tha air an eilean seo - tha iad a bruidhinn tòrr Gàidhlig agus chan eil really àite sam bith eile [ann an Alba]." Well, yes on this island - they speak lots of Gaelic but not really anywhere else [in Scotland]." (Hazel)

However, other children identified that Gaelic was spoken throughout Scotland, albeit it by a minority, and that there was increased public interest in Gaelic, and in learning Gaelic:

"Daoine mar, ma tha iad a' tighinn suas an seo chan eil Gàidhlig... tha iad...airson Gàidhlig fhaighinn. Agus. Ach tha Gàidhlig aig tòrr daoine."

"People like, if they are coming up here they don't have Gaelic...they want to learn Gaelic. And. But plenty of folk have Gaelic.” (Pàdraig)

Pàdraig explained, however, that Gaelic was "virtually wiped out" in parts of the mainland, whereas it had been at once the dominant language of Scotland.

Most children had been to other places where they had heard Gaelic being spoken, including towns such as Glasgow and Inverness, and other islands in the so-called heartlands, but they also had an awareness of how special their island was in maintaining the language and they valued their own role in sustaining the islands' cultural identity. Connectedly, 15 children agreed or strongly agreed with the statements 'it's better to be bilingual than monolingual' and 'I enjoy having two languages'. Research has identified the cognitive, social and cultural benefits of being bilingual or multilingual, and some children were aware that being bilingual helps them to learn an additional language and were in fact learning French at school.

The weakest mean score was recorded for children's attitudes towards their current use of Gaelic. Thirteen agreed, or strongly agreed with the statement 'I like speaking Gaelic' and the remainder were neutral. When it came to using Gaelic outside of the education system, some children were less confident. Only three children disagreed with the statement 'I don't like using Gaelic outside of school'; nine were neutral and six were in agreement. Children's understanding of their own bilingual proficiency and use is explored in more detail in the following section.

\section{Children's Language Practices}

\section{Children's Understanding of their Bilingual Proficiency}

Previous research has indicated that children in Gaelic medium perform better in English than they do in Gaelic at the P7 stage (O'Hanlon et al., 2010). There is anecdotal evidence from teachers reporting that the children's English language skills are more advanced than their Gaelic skills. 
We were interested to find out whether children felt more or less comfortable using English or using Gaelic for different tasks. Our survey asked the children to rate on a five-point scale how happy they were when speaking, reading, writing and spelling in each language (Table 1). The highest combined mean scores were for speaking skills, and the lowest for spelling. The survey showed that children were, on average, more positive about their use of English for these activities than their use of Gaelic. The gap between the mean scores for English and Gaelic were largest for reading (.61) and writing (.56). There was little difference in the mean score for speaking English and Gaelic, and less variance across the sample.

Table 1: Children's Attitudes Towards their Bilingual Skills

Thinking of the different things you do at school, how do you feel about:

\begin{tabular}{|c|c|c|c|c|c|c|c|}
\hline & $\mathrm{N}$ & Min. & Max. & Mean & $\begin{array}{c}\text { Std. } \\
\text { Deviation }\end{array}$ & Average & Difference \\
\hline $\begin{array}{l}\text { Sgrìobhadh sa Ghàidhlig } \\
\text { (Writing in Gaelic) }\end{array}$ & 18 & 2 & 5 & 3.72 & .958 & & \\
\hline $\begin{array}{l}\text { Sgriobhadh sa Bheurla } \\
\text { (Writing in English) }\end{array}$ & 18 & 2 & 5 & 4.28 & .895 & 4.0 & 0.56 \\
\hline $\begin{array}{l}\text { Leughadh sa Ghàidhlig } \\
\text { (Reading in Gaelic) }\end{array}$ & 18 & 1 & 5 & 3.56 & 1.149 & & \\
\hline $\begin{array}{l}\text { Leughadh sa Bheurla } \\
\text { (Reading in English) }\end{array}$ & 18 & 2 & 5 & 4.17 & .924 & 3.9 & 0.61 \\
\hline $\begin{array}{l}\text { Litreachadh sa Ghàidhlig } \\
\text { (Spelling in Gaelic) }\end{array}$ & 18 & 1 & 5 & 3.61 & 1.243 & & \\
\hline $\begin{array}{l}\text { Litreachadh sa Bheurla } \\
\text { (Spelling in English) }\end{array}$ & 18 & 1 & 5 & 3.78 & 1.215 & 3.7 & 0.17 \\
\hline $\begin{array}{l}\text { Bruidhinn sa Ghàidhlig } \\
\text { (Speaking in Gaelic) }\end{array}$ & 18 & 2 & 5 & 4.28 & .958 & & \\
\hline $\begin{array}{l}\text { Bruidhinn sa Bheurla } \\
\text { (Speaking in English) }\end{array}$ & 18 & 3 & 5 & 4.39 & .778 & 4.3 & 0.11 \\
\hline $\mathrm{N}$ & 18 & & & & & & \\
\hline
\end{tabular}

$(1=$ completely unhappy $2=$ a little unhappy $3=$ OK $4=$ happy enough and $5=$ completely happy)

At a disaggrated level, the combined mean scores for the group of four English skills as compared to the mean score for the four Gaelic skills show that four children are happier, on average, using Gaelic than using English and for two, there is no difference in the scores. The remainder (12), on average, feel happier using English for these activities than Gaelic.

Three children have a very positive attitude towards their Gaelic skills, two of whom have Gaelic in the home and a high 'density' of networks to speak Gaelic: but the third had not spoken Gaelic to anybody outside the school in the week prior to the study. However, whilst there is not a statistically significant relationship between the density of pupils' Gaelic-speaking networks and their Gaelic language skills, there is significant relationship between children's Gaelic language skills and English language skills $(r=0.557, p=0.01)$. With such a small sample, it is not possible to extrapolate from these findings. However if this pattern were replicated in a much larger sample, then it would 
suggest that Gaelic-medium is successfully socialising children into being confident Gaelic users.

Our interviews explored further the children's perceptions of their own competence, and their attitudes towards using Gaelic and English. Children who understood their English skills to be generally stronger than their Gaelic skills had no Gaelic at home, and explained that they did not have the same breadth of vocabulary in Gaelic as they have in English and that they were dependent upon the teacher for Gaelic language learning. Christopher explained:

"[T] ha mi nas fheàrr air Beurla oir chan eil tòrr, mar, cuideachadh agam airson Gàidhlig ach an tidsear agam, so..." (Christopher)

"I am better at English because I don't have much, like, help for Gaelic but my teacher, so..."(Christopher)

He understood his Gaelic language skills in relation to others in the class, who had greater language input at home:

"Uill, tha Seòras ann an clas againn; tha esan uabhasach math air Gàidhlig oir tha a h-uile duine bruidhinn Gàidhlig ann an taigh aige, mar sin, tha e math air Gàidhlig." (Christopher)

"Well, Seòras in our class, he is really good at Gaelic because everyone in his home speaks Gaelic, so, he is good at Gaelic." (Christopher)

It was more common, however, for the children to express that they were at least as comfortable in Gaelic as in English, and several told us were more confident in writing in Gaelic than English.

\section{Code-switching and mixing}

The dominant model of 'Gaelic-medium education' has been bounded primary school 'units' and more recently stand-alone schools with the current recommendation that pupils be 'totally immersed' for the first three years, before English is gradually introduced as a language subject. As per García (2009: 124-5), Gaelic medium education in Scotland is orientated towards a 'diglossic' (additive bilingual model) since the framework involves working towards the development of the students' bilingualism according to two monoglossic standards. The ideology of Gaelic as the 'medium of instruction' is based on treating Gaelic and English as separate codes. More recent research based on classroom observation notes, however, that code-switching and translanguaging is prevalent in teachers, as well as in pupils (Will 2012). We wished to explore, therefore, the children's understanding of the interaction between the two languages, and their use of code-switching and mixing. 
The survey asked whether children agreed with the statement 'I mix Gaelic and English when I am speaking'; only four agreed with this statement. Our interview data, as well as our classroom observation, suggests that this result reflects the dominance of English monolingual speech outside the classroom rather than the use of English when in a Gaelic dominant context. It is also likely to reflect, however, the effort to treat Gaelic and English as separate codes in the classroom or in other Gaelic-speaking contexts outside of school.

In interview children told us that they would borrow from English to fill lexical gaps, modelling a practice they observed in adult speakers, but they were very conscious of upholding Gaelic as the normative language when, for example, in the Gaelic class or at Sradagan:

"Direach uaireannan ma tha mi, mar, stuck air facal agus an uair sin tha mi direach, mar, ag ràdh facal Beurla is uaireannan, mar, bidh daoine gam cuideachadh faighinn am facal Gàidhlig." (Hazel)

"Just sometimes if I'm, like, stuck on a word and then I just like, say an English word sometimes, like, people will help me get a word in Gaelic." (Hazel)

Lee explained that this was something that did concern her in the classroom, but that her general strategy was to ask the teacher, or to consult the dictionary. Isabella clarified, however, that this was a practice only necessary for written work, such as when writing a story, but otherwise she would say the word in English - and then, if overheard, the teacher would supply the Gaelic vocabulary to her or if relevant, to the whole class. Unsolicited use of English in the classroom, they explained, was typically corrected by the teacher, and switching unconsciously to Gaelic in the playground was self-corrected.

\section{Out of Class Bilingual Practices}

There is no national school-level data on pupils according to their home language use. Forthcoming output from the 2011 census will generate figures on the number of children who live in Gaelic-speaking homes, but meantime, the only data available is from the Annual Pupil Census. The Annual Pupil Census tells us that only 510 school pupils categorise Gaelic as their 'home language' (Scottish Government, 2018) and whilst these data are unreliable, it suggests a significant majority of the c. 2600 children in Gaelic-medium education live in homes in which Gaelic is not used, or is not the main language. Children's opportunities for Gaelic early years language socialisation, social use, and even the duration of their time in Gaelic-medium education can vary.

The school questionnaire elicited data which indicate languages spoken by their parents. Relative to parental use amongst young Gaelic speakers in general, the study cohort has a relatively high opportunity to use Gaelic in the 
home: 14 of 18 children live in households with a Gaelic-speaking parent, and six children's parents both speak Gaelic. The survey also asked young speakers whether they had spoken Gaelic during the past week with their parents, siblings, friends or neighbours. Five children had spoken no Gaelic to family, friends or neighbours the week prior to the school visit; three children had spoken to people in all six categories, suggesting that Gaelic was one of the languages of the home and that their Gaelic language networks were denser than their fellow students. Only half of the eighteen children had used Gaelic with friends or neighbours outside of the classroom. Twelve of eighteen children told us that they had, however, spoken Gaelic to either their mother or father in the week prior to our visit.

Table 2: The use of Gaelic by young speakers

\begin{tabular}{lcc}
\hline In past week, spoke Gaelic to: & No. & $\%$ \\
\hline Mother & 10 & 56 \\
Father & 9 & 50 \\
Brother/s & 6 & 33 \\
Sister/s & 7 & 39 \\
Friends & 7 & 39 \\
Neighbours & 5 & 28 \\
\hline
\end{tabular}

However, when compared with our interviews later, the children revealed that the use of Gaelic in many households was limited. Children explained this could be due to for example, only one of their parents speaking Gaelic, or because a parent was learning to speak Gaelic, but was not yet fluent. For children who lived in households where Gaelic was not commonly used, their use of Gaelic in the home was typically infrequent and parent-child Gaelic use was confined to particular kinds of exchanges. For example, one child told us that her father would read to her in Gaelic when helping with homework, but would discuss the homework in English, due to a lack of confidence or proficiency. Another told us that her father was too shy to speak Gaelic to her, or to anyone, although he could: "cha toil e a' bruidhinn mar, duine, mar, tha e kind of shy..." (He doesn't, like, talking (to) people, like, he is kind of shy".

We prompted the children to give examples of when they did use Gaelic in a home setting- these included when an older speaker, such as Grandparents or friends of parents, were visiting or the children were visiting them. Respecting the language preference of elders is the norm in Gaelic-speaking communities, and the presence of Gaelic-speaking elders has been found to initiate a switch to Gaelic (e.g. Smith-Christmas and Smackman 2009). In our study, one child told us that she only speaks Gaelic to her sister when her Gaelic-speaking 
grandparents are present. Research on Welsh language has indicated the strong influence of extended family members on minority language development (Morris and Jones 2009). Grandparents play an important role in /Gaelic language use, which in turn, gives these children access to proficient speakers in a non-school setting and it provides them with opportunities to use Gaelic.

Several of the children had siblings who were also in Gaelic medium schooling, and they told us how their parents would encourage them to use Gaelic together. Lee, however, found it difficult to articulate why using Gaelic with her brother in a home setting was at odds with her sense of Gaelic-speaking self:

\begin{tabular}{|c|c|}
\hline \multirow[t]{2}{*}{ Interviewer } & $\begin{array}{l}\text { Agus am bi thu fhèin agus Christopher bruidhinn Gàidhlig ri } \\
\text { chèile aig an taigh? }\end{array}$ \\
\hline & Do yourself and Christopher speak Gaelic together at home? \\
\hline Lee: & $\begin{array}{l}\text { Uaireannan bidh dadaidh dìreach a' canadh rium is bruidhinn } \\
\text { Gàidhlig gu - mar, bruidhinn Gàidhlig gu, mar, agus bidh sinn a' } \\
\text { bruidhinn Gàidhlig. Tha e really, tha e beagan diofraichte oir tha } \\
\text { sinn a' bruidhinn Gàidhlig ann an taigh ach chan eil sinn really } \\
\text { bruidhinn Beurla ann an sgoil so tha e..... } \\
\text { Sometimes Daddy will just say to me speak Gaelic to - like, } \\
\text { speak Gaelic to, like, and we will speak Gaelic. It is really, it is a } \\
\text { little different because we are speaking Gaelic at home and we are } \\
\text { not really speaking English in school so it is..... }\end{array}$ \\
\hline Interviewer & $\begin{array}{l}\text { Anns an sgoil, sa chlas tha sibh bruidhinn Gàidhlig ri chèile? } \\
\text { In school, in class you speak Gaelic with each other? }\end{array}$ \\
\hline Lee: & Uh-huh. \\
\hline Interviewer & $\begin{array}{l}\text { Agus a bheil e neònach nuair a thèid sibh dhachaidh agus dè tha } \\
\text { sibh bruidhinn ri chèile mar is trice nuair a tha sibh aig an taigh? } \\
\text { And is it strange when you go home and what do you speak to } \\
\text { each other usually when you're at home? }\end{array}$ \\
\hline Lee: & $\begin{array}{l}\text { Direach, mar, bruidhinn Beurla. } \\
\text { Just like speak English. }\end{array}$ \\
\hline
\end{tabular}

As such, children with Gaelic-speaking siblings in largely monolingual home settings told us that Gaelic was the natural language of social interaction at school, but English the natural main language of social interaction at home. In this study, it became clear that only children who live in households where one or more parents are fluent, active speakers, have daily access to 'proficient' users of Gaelic. Several children told us how they watched programmes on the Gaelic television channel, BBC Alba, at home, and linked this to their own language development.

A low level of Gaelic language use in the home is supported by previous research which indicates low Gaelic language use between parents who have some level of Gaelic and their children (Stockdale et al. 2003). Research by O' 
Hanlon et al. (2013) on public attitudes to Gaelic in Scotland has indicated that the public perceive parents who speak Gaelic as having the most responsibility for ensuring that Gaelic is spoken in Scotland. However, our research highlights that mixed-language households are the norm, and that Gaelic-speaking parents who seek to implement strategies for normalising the use of Gaelic are not necessarily successful. The discussion around Gaelic homework would seem to be an important link in terms of Gaelic language in the classroom and in the home, and could be an area where parents who are learning the language could build upon their use of Gaelic language with their children.

The findings here support anecdotal evidence and the findings of $O$ ' Hanlon et al. (2012). Whilst Gaelic is the normative language of the classroom, outside English is the norm, even when interacting with pupils from Gaelic class. Children interviewed told us that they tend not to speak Gaelic in the corridor, cloakroom or playground and will switch from English to Gaelic as they enter the classroom because they recognise that they are entering a setting in which they are expected to speak Gaelic, and in which it is the norm to do so. The role of teacher, who has the authority to control code choice, is important, as Lee and Dawn explain:

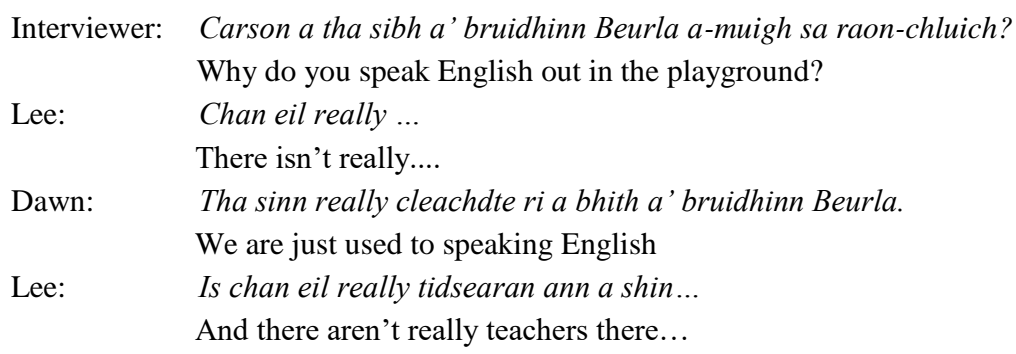

Other children explained that they use English in the playground because children 'in English' were present and because there was no need to use Gaelic. The norm of using the 'language of inclusion' in the playground (Thomas and Roberts 2011; Hickey 2001) was something that children were conscious of upholding, and therefore, of breaking, as Pàdraig describes here:

"Uill tha duine a' bruidhinn Beurla ach uaireannan direach, mar, bidh sinn 'accidently' bruidhinn Gàidhlig! Ach, bidh sinn, uaireannan tha sinn dol a-mach agus chan fhaod sinn a' bruidhinn Beurla agus tha feum againn a' bruidhinn Gàidhlig." (Pàdraig)

"Well, people speak English [in the playground] but sometimes just, like, we 'accidentally' speak Gaelic! But we will, sometimes we are going out and we can’t speak English, we have to speak Gaelic.” (Pàdraig) 
On the other hand, one speaker appeared less sensitive to such language norms and was confident in asserting a Gaelic-speaking identity. He had previously attended a 'Gaelic school', and was involved in the shinty and football teams. He told us he used both Gaelic and English with friends in the playground or when playing sport, although to what extent it was unclear:

“Uaireannan bidh mi a' bruidhinn Gàidhlig gu, mar, em, mar caran leth no cairteal de na caraidean agam - ,'s toil leothsan a bhith bruidhinn Gàidhlig. Ach tha mi a' bruidhinn Gàidhlig gu an nàbaidh agam oir tha Gàidhlig aicese." (Christopher).

"Sometimes I speak Gaelic to, like, em, like about half or quarter of my friends they like to speak Gaelic. But I speak Gaelic to my neighbour because she has Gaelic." (Christopher)

It was striking, however, how restricted children's use of Gaelic was outside of school. Few of the children interviewed were engaged in Sradagan, Gaelicspeaking youth clubs, or Fèisean, music-based festivals for children. This was reflected in the ambivalence children held towards the statement 'I don't like using Gaelic outside of school': only three children disagreed or strongly disagreed with this, nine were neutral and six were in agreement. This is despite children's positive attitudes towards speaking Gaelic and being bilingual. Children seldom need to negotiate using Gaelic outside of school and for most, its use is 'reserved' for the occasions when it is socially appropriate to do so. These include Fèisean, summer clubs and Mòds (local festivals celebrating the Gaelic language), at which some of the children take part in competitions for Gaelic solo and choral singing or poetry recitation.

\section{Conclusions}

Overall, we found that children generally held a very positive attitude towards the Gaelic language and towards their bilingual, Gaelic-speaking identities. The children were more positive about the perception of others towards their identity as Gaelic speakers and towards bilingualism in general, however, than they were about their own language practices. The majority of children have, on average, more confidence in their use of English for reading, writing, spelling and speaking skills, than Gaelic. On the other hand, there was little difference in the mean score for speaking English and Gaelic, and less variance across the sample. The children are confident Gaelic speakers. This is despite these findings: 
- only six of the eighteen children live in households in which both parents can speak Gaelic (to some degree);

- a sizeable minority of six are likely to have no Gaelic input in the home;

- most children have very limited opportunity to use Gaelic outside of the classroom or the family home.

This suggests that this Gaelic-medium school is successfully socialising children into being confident Gaelic users in the classroom, trying to find innovative ways to maintain Gaelic as their normative language. The children express some uncertainty, however, about their future expectation of use which suggests a lack of confidence in Gaelic's relevance beyond their education, a point borne out by Dunmore's work (e.g. 2014) on school leavers. If it can be extrapolated from this small case-study that similar usage and attitudes could be found elsewhere, the positivity of these young speakers and their commitment to the language which ultimately does not result in all of them becoming Gaelic-speaking adults shows language planners that targeted intervention need take place to support the young speakers to continue their paths as Gaelic users into adulthood. It is hoped that a bigger study of this nature might shed further light on practices and ideologies of speakerhood which could inform interventionist strategy.

\section{REFERENCES}

Auer, Peter. 1984. Bilingual Conversation. Amsterdam: John Benjamins.

Baker, Colin. 1992. Language and Attitudes. Clevendon: Multilingual Matters.

Baker, Colin. 2006. Foundations of Bilingual Education and Bilingualism. Clevedon: Multilingual Matters.

Cohen, Louis, Lawrence Manion, and Keith Morrison. 2000. Research Methods in Education (5th Edition). London: Routledge Falmer.

Creswell, John W. 2012. Educational research: Planning, conducting, and evaluating quantitative and qualitative research (4th ed.). Boston, MA: Pearson

Dunmore, Stuart. 2014. Bilingual life after school?: Language use, ideologies and attitudes among Gaelic-medium educated adults. University of Edinburgh: Unpublished Doctoral Thesis

Dunmore, Stuart. 2017. "Immersion education outcomes and the Gaelic community: identities and language ideologies among Gaelic medium-educated adults in Scotland", Journal of Multilingual and Multicultural Development, 38:8: 726-741, DOI: 10.1080/01434632.2016.1249875.

Education Scotland, 2007. Curriculum for Excellence, Literacy and Gàidhlig, Principles and Practice, Scotland.

Fishman, Joshua A. 2006. "Language Policy and Language Shift", in: Thomas Ricento (ed.). An Introduction to Language Policy: Theory and Method. Oxford: Blackwell Publishing. 
García, Ofelia. 2009. Bilingual Education in the 21st century: A global perspective. Malden MA and Oxford: Wiley/Blackwell.

Hickey, Tina. 2001."Mixing beginners and native speakers in minority language immersion: who is immersing who?" The Canadian Modern Language Review, 57(3): 443-474.

Hinton, Leanne. 2011. "Language revitalization and language pedagogy: new teaching and learning strategies". Language and Education 25:4: 307-318, DOI: $\underline{10.1080 / 09500782.2011 .577220}$

HM Inspectorate of Education. 2011. Gaelic Education: Building on the Successes, Addressing the Barriers. Livingstone: HM Inspectorate of Education.

Johnstone, Richard, Wynne Harlen, Morag MacNeil, Bob Stradling and Graham Thorpe. 1999. The attainment of pupils receiving Gaelic medium education in Scotland. Stirling: Scottish Centre for Information on Language Teaching and Research.

Johnston, Richard. 2002. Immersion in a Second or Additional Language at School: A Review of the International Research. Stirling: Scottish CILT.

MacLeòid, Dòmhnall Iain. 2007. "Sùil air ais", in: Mairead NicNeacail and Mata M. Maclomhair (eds.) Foghlam tro Mheadhan na Gàidhlig. Edinburgh: Dunedin Academic Press, 1-15.

MacLeòid, Dòmhnall Iain. 2008. Dòigh Eile Air a Ràdh. Stòrlann Nàiseanta na Gàidhlig.

McLeod, Wilson. 2004. "The challenge of corpus planning in Gaelic development". Scottish Language 23: 68-92.

Morris, Delyth and Kathryn Jones. 2009. "Minority Language Socialisation within the Family: Investigating the Early Welsh Language Socialisation of Babies and Young Children in Mixed Language Families in Wales”. Journal of Multilingual and Multicultural Development, 28(6): 484-501.

Myers-Scotton, Carol. 2006. Multiple Voices: an Introduction to Bilingualism. Malden MA: Blackwell Publishers.

Ó Domhnalláin, Tomás. 1977. „Ireland: The Irish language in education”. Language Problems \& Language Planning Vol.1 (2): 83-96.

Nance, Claire. 2013. Phonetic variation, sound change, and identity in Scottish Gaelic University of Glasgow: Unpublished Doctoral Thesis

Nance, Claire. 2015. “'New' Scottish Gaelic speakers in Glasgow: a phonetic study of language revitalisation". Language in Society 44 (4): 553-579.

NicLeòid, Sìleas. 2015. A' Ghàidhlig agus Beachdan nan Sgoilearan: Cothroman leasachaidh ann am Foghlam tro Mheadhan na Gàidhlig. Slèite: Clò Ostaig.

Nisbet, John and Joyce Watt. 1984. "Case Study", in: K. Bell et al. (eds.), Conducting SmallScale Investigations in Educational Management. London: Harper \& Row.

O'Hanlon, Fiona, Wilson McLeod and Lindsay Paterson. 2010. Gaelic-Medium Education in Scotland: Choice and Attainment at the Primary and Early Secondary School Stages. Inverness: Bòrd na Gàidhlig.

O'Hanlon, Fiona. 2010b. "Gaelic in upper primary schools in Scotland: policy and practice", in: Gillian. Munro and Iain. Mac an Tàilleir (eds.). Coimhearsnachd na Gàidhlig anDiugh/Gaelic Communities Today. Edinburgh: Dunedin Academic Press: 99-115.

O'Hanlon, Fiona, Wilson McLeod and Lindsay Paterson. 2012. Language Models in Gaelicmedium Pre-school, Primary and Secondary Education. Soillse (http://www.soillse.ac.uk/wp-content/uploads/Modailean-C\%C3\%A0nain-ann-amFoghlam-Ro-sgoile-Bun-sgoile-agus-\%C3\%80rd-sgoile-MeadhainGh\%C3\%A0idhlig_6.pdf) 
O’Hanlon, Fiona and Lindsay Paterson. 2015. "Gaelic Education since 1872”, in: Mark Freeman, Robert Anderson and Lindsay Paterson (eds), The Edinburgh History of Education in Scotland. Edinburgh: Edinburgh University Press, 304-325.

Stake, Robert E. 1995. The Art of Case Study Research. Thousand Oaks: Sage Publications.

Stockdale, Aileen, Bryan MacGregor and Gillian Munro. 2003. Migration, Gaelic-medium Education and Language Use. Ionad Nàiseanta na h-Imrich, Sabhal Mòr Ostaig.

Thomas, Enlli Môn and Dylan Bryn Roberts. 2011. "Exploring bilinguals' social use of language inside and outside of the minority classroom". Language and Education 25(2): 89108.

Vila i Moreno, F. Xavier. 2008. "Language-in-education policies in the Catalan area". AILA Review 21: 31-48.

Will, Vanessa. 2012. Why Kenny Can't Can: The Language Socialization Experiences of GaelicMedium Educated Children In Scotland. University of Michigan: Unpublished PhD Thesis.

Yin, Robert K. 2009. Case Study Research and Applications: Design and Methods (4 ${ }^{\text {th }}$ Ed.). Thousand Oaks, CA: Sage. 